\title{
Síndroma antifosfolipídica: a propósito de um caso clínico
}

Lisa Teresa Moreira, ${ }^{1-2}$ Ricardo Torre, ${ }^{1,3}$ Joana Barbosa, ${ }^{1,4}$ Maria Luísa Ferreira, ${ }^{1,4}$ Maria Antónia Cruz, ${ }^{4,5}$

\section{RESUMO}

Introdução: A síndroma antifosfolipídica é uma doença autoimune que confere maior suscetibilidade para eventos trombóticos, podendo atingir qualquer território vascular e uma multiplicidade de manifestações clínicas que tornam o seu diagnóstico um desafio.

Descrição do caso: Uma mulher de 25 anos, caucasiana, recorre à consulta por cefaleia frontal direita, com irradiação para a região ocular, associada a hipostesia da hemiface direita e apagamento do sulco nasogeniano direito. Realizou tomografia computorizada crânio-encefálica (TC-CE) que não evidenciou alterações. Após 48 horas, por agravamento das queixas com aparecimento de "adormecimento" (sic) do hemicorpo direito repetiu TC-CE que revelou trombose dos seios venosos (terços anterior e médio do seio longitudinal superior). A investigação etiológica determinou a presença do inibidor lúpico, anticorpos antinucleares (1/320 padrão mosqueado) e anticorpo anti- $\beta 2$-glicoproteina, tendo sido estabelecido o diagnóstico de síndroma antifosfolipídica.

Comentário: O acidente vascular cerebral (AVC) é a forma de apresentação da síndroma antifosfolipídica em 13,5\% a 15\% dos doentes, com um atingimento predominante da artéria cerebral média. $O$ atingimento dos seios venosos é uma forma de apresentação rara e que se associa a manifestações clínicas inespecíficas. O diagnóstico precoce de AVC nos jovens permanece difícil e a necessidade de sensibilização da equipa de saúde para esta problemática urge, especialmente com a concomitante emergência de fatores de risco em adultos jovens relacionados com a epidemia da obesidade.

Palavras-chave: Síndroma antifosfolipídica; Anticorpo antifosfolipídico; Acidente vascular cerebral; Trombose dos seios venosos.

\section{INTRODUÇÃO}

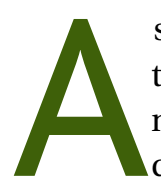

síndroma antifosfolipídica é uma doença autoimune associada a elevada morbilidade e mortalidade por conferir maior suscetibilidade para eventos trombóticos de natureza arterial ou venosa. ${ }^{1-3}$ Estima-se que seja a causa pró-trombótica adquirida mais comum, com uma prevalência de $2 \%$. É mais frequente no sexo feminino, dos 15 aos 50 anos, com idade média de diagnóstico aos 34 anos. $^{3-4}$

Pode atingir virtualmente qualquer território vascular. Logo, as manifestações clínicas variam desde a trombose venosa profunda, tromboembolismo pulmonar, acidente vascular cerebral (AVC), doença coronária isquémica, doença valvular, estenose da artéria

1. Médico Interno de Medicina Geral e Familiar

2. ACeS Tâmega II, Vale do Sousa Sul

3. ACeS Grande Porto I, USF Veiga do Leça

4. ACeS Tâmega II, USF Nova Era

5. Médica Assistente Graduada de Medicina Geral e Familiar renal, livedo reticular, necrose cutânea, morte fetal, entre outras, tornando o seu diagnóstico um desafio. ${ }^{1-3,5-6}$

A síndroma antifosfolipídica não é uma situação clínica frequente, pelo que no caso clínico descrito surgiram dificuldades diagnósticas, mas que permitiram sensibilizar os clínicos para a presença de eventos trombóticos em idades jovens.

\section{DESCRIÇÃO DO CASO CLÍNICO}

Maria, sexo feminino, 25 anos, caucasiana, autónoma, estudante de contabilidade e trabalhadora em tempo parcial como funcionária fabril. É a primeira numa fratria de dois (Figura 1). Vive em união de facto, na fase I do ciclo de vida familiar, com um Apgar familiar de 9 (família altamente funcional).

Apresenta, como antecedentes pessoais, obesidade (índice de massa corporal: $34,4 \mathrm{Kg} / \mathrm{m}^{2}$ ) e trombocitopenia (desde há dois anos, de etiologia desconhecida). A história clínica revelou não haver alergias, hábitos tabágicos ou etílicos, acidentes, traumatismos, interna- 


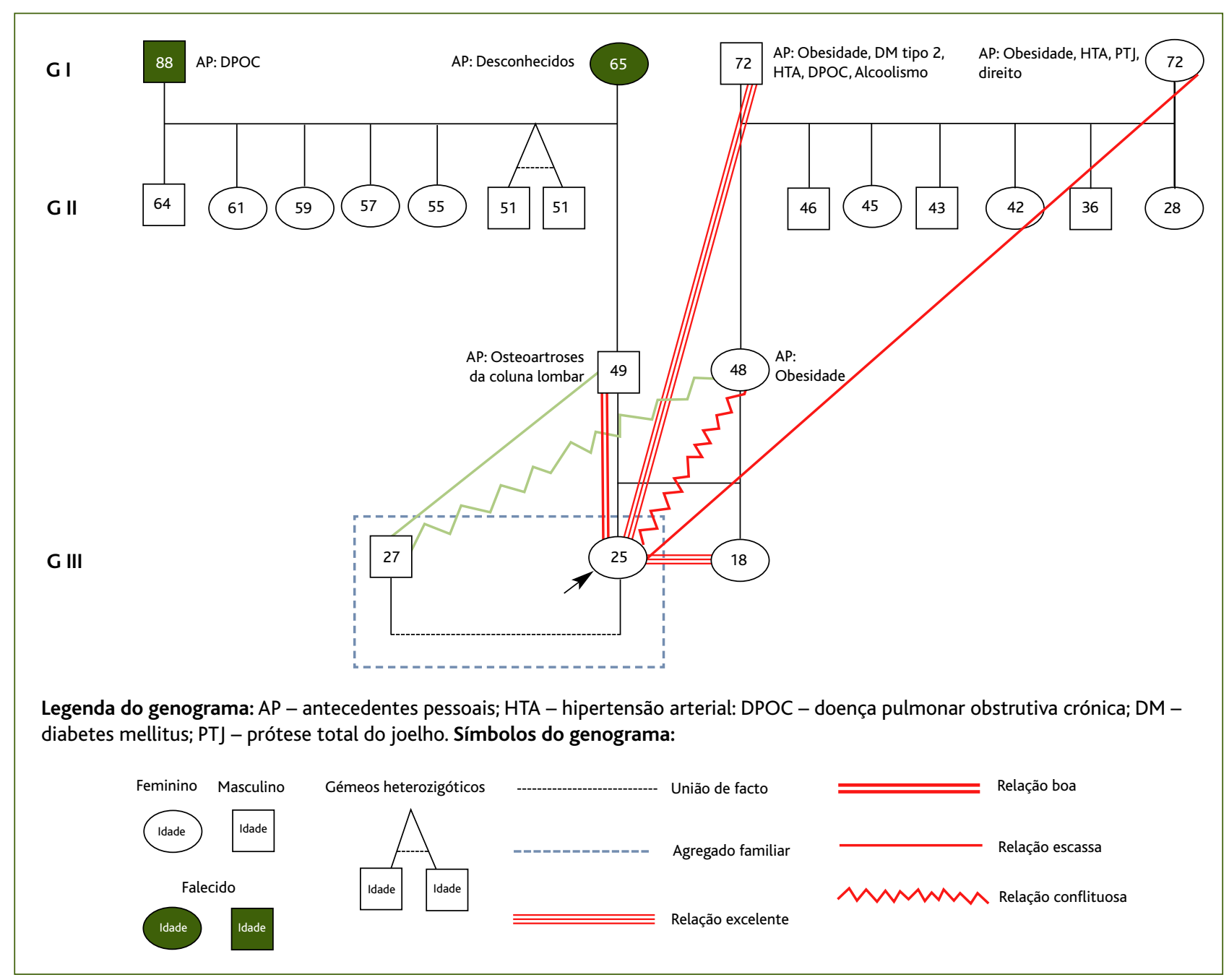

Figura 1. Genograma com psicofigura de Mitchell e antecedentes familiares (abril de 2015).

mentos, intervenções cirúrgicas prévias, transfusões ou imunizações recentes. História ginecológica e obstétrica: zero gestações e sem história de abortos, medicada com anticoncetivo hormonal combinado (anel vaginal: etonogestrel 0,120mg / etinilestradiol 0,015mg) desde há um ano (sem outra terapêutica crónica). Realiza 30 minutos de atividade física duas vezes por semana e vive em habitação própria, com eletricidade, água potável e saneamento básico. Sem viagens recentes ao estrangeiro.

Tem um primo materno em $2^{\circ}$ grau com antecedentes de AVC aos 32 anos e uma prima materna em $2^{\circ}$ grau com antecedentes de AVC da artéria cerebral mé- dia aos 16 anos. Tem ainda outros fatores de risco familiares, como hipertensão arterial e diabetes mellitus tipo 2 (Figura 1).

Maria iniciou quadro súbito de dor persistente na região frontal direita de grande intensidade, tendo recorrido ao serviço de urgência (SU) no mesmo dia. Após observação clínica foi-lhe diagnosticada cefaleia, tendo tido alta com nimesulide 100mg em SOS.

Após quatro dias recorreu à consulta aberta na sua Unidade de Saúde Familiar (USF) por manutenção do quadro de cefaleia persistente na região frontal direita, de início súbito e de grande intensidade (escala numérica: 7-8, em 10), em moinha, com irradiação para a re- 

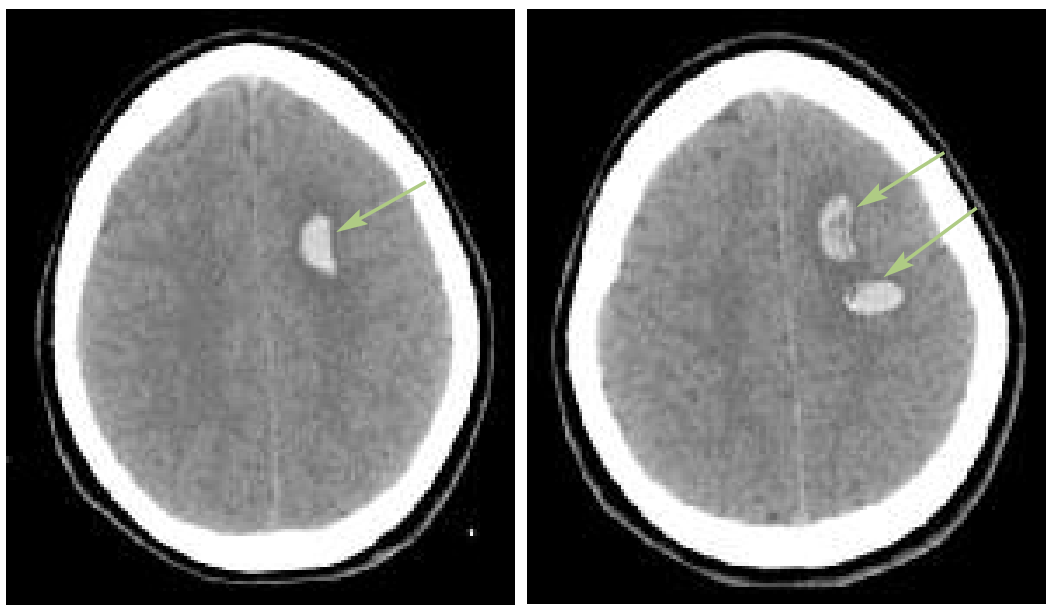

Figura 2. TC-CE: Setas - Área de hiperdensidade, sinais compatíveis com hematoma agudo frontal esquerdo.

gião ocular, que não aliviava com a terapêutica instituída. Referia ainda hipostesia da hemiface direita, halos luminosos, fotofobia e dificuldade de concentração. Negava febre, dor à mobilização ocular, movimentos involuntários, descoordenação motora, vertigens, alterações cutâneas, traumatismo ou outras queixas.

O exame objetivo detalhado estava normal, à exceção do exame neurológico. A doente apresentava-se consciente, colaborante, comunicativa e orientada; discurso ligeiramente lentificado, mas fluente, sem afasia ou outras alterações da linguagem; pupilas fotoreativas; oculomotricidade preservada, sem nistagmo ou diplopia; campos visuais normais pelo teste de confrontação; apresentava diminuição da sensibilidade da hemiface direita para estímulos álgicos e táteis; ligeiro apagamento do sulco nasogeniano à direita e desvio da comissura labial para a esquerda; sem alterações motoras do andar superior da face; tónus, força global e força segmentar preservada e simétrica nos quatro membros (escala de avaliação da força muscular Medical Research Council); reflexos osteoarticulares preservados; sem dismetrias na prova dedo-nariz; marcha e prova de Romberg normal; sinais meníngeos negativos.

Perante o quadro clínico colocaram-se as hipóteses diagnósticas de AVC, lesão ocupante de espaço, enxaqueca com aura ou cefaleia de cluster, pelo que foi encaminhada para o SU.

No SU, o eletrocardiograma (ECG) e a tomografia computorizada crânio-encefálica (TC-CE) não eviden- ciaram qualquer alteração, pelo que a doente teve alta com indicação para manter analgesia com nimesulide 100mg em SOS.

Após 48 horas recorreu novamente à consulta aberta na USF por agravamento do quadro prévio, com aparecimento progressivo de "adormecimento" (sic) do hemicorpo direito. Apresentava diminuição da sensibilidade (álgica e tátil) e da força muscular ipsilateral ao exame físico, pelo que foi novamente encaminhada para o SU por suspeita de AVC.

Dos exames realizados no SU, a doente apresentava leucocitose com neutrofilia, trombocitopenia e elevação da proteína C reativa (PCR) (leucócitos: 12.700 x10 $/$ L; neutrófilos: $84,7 \%$, plaquetas: $77.000 \times 10^{3} / \mathrm{L}$; PCR $26,4 \mathrm{mg} / \mathrm{dL}$ ). Repetiu ECG que não demonstrou alterações e TC-CE que revelou: "Hematoma agudo frontal esquerdo, de 25x11 mm, com área de edema vasogénico perifocal e discreta hemorragia subaracnoidéia em alguns sulcos corticais parietais e frontais" (Figura 2).

No decurso da observação no SU apresentou como intercorrência crise convulsiva tónico-clónica generalizada com duração de 30 segundos, tendo tido recuperação progressiva espontânea do estado de consciência. Foi medicada com valproato de sódio e iniciou anticoagulação com enoxaparina.

Nesta fase apresentava-se sonolenta com abertura espontânea dos olhos, cumpria ordens simples, com discurso escasso e lentificado (Glasgow de 13); possível hemianópsia homónima direita, sem anosagnosia, sem extinção visual ou sensitiva; reflexo do vómito ausente; paresia facial do andar inferior direito; hemi-hipostesia direita e hemiparesia direita, com força muscular grau 0 em 5 no membro superior direito e força muscular grau 3 em 5 no membro inferior direito; reflexo cutâneo plantar extensor à direita; NIHSS:7 (National Institutes of Health Stroke Scale) e mRankin:3 (modified Rankin Scale).

Para melhor caraterização da lesão realizou angio-TC crânio que revelou trombose dos seios venosos (terços anterior e médio do seio longitudinal superior) com transformação hemorrágica, tendo ficado internada.

Durante o internamento, a doente evoluiu favoravelmente com melhoria progressiva dos défices neuro- 
QUADRO I. Evolução durante o internamento

D1 Intercorrências: Duas crises convulsivas tónico-clónicas generalizadas. Uma reverteu espontaneamente, a outra após $10 \mathrm{mg}$ de diazepam retal. Iniciou levetiracetam.

TC-CE de controlo pós crise convulsiva: Nova lesão hemorrágica na vertente lateral do hemisfério cerebeloso esquerdo. EEG: "Atividade de base normal. Abundante atividade lenta disfuncional generalizada e sobretudo frontotemporal. Não se registam atividades epileptiformes".

D6 TC-CE de controlo: "Sinais de reabsorção parcial. As amígdalas cerebelosas afloram os limites do buraco magno."

RMN-CE para exclusão de herniação amigdalina: "Amígdalas cerebelosas em topografia normal." "Sinais compatíveis com trombose venosa dos dois terços anterior e médio do seio longitudinal superior" (Figura 3):

Figura 3. FRMN-CE (T2): Seta - Área de hiperintensidade, sinais compatíveis com trombose venosa do seio longitudinal superior
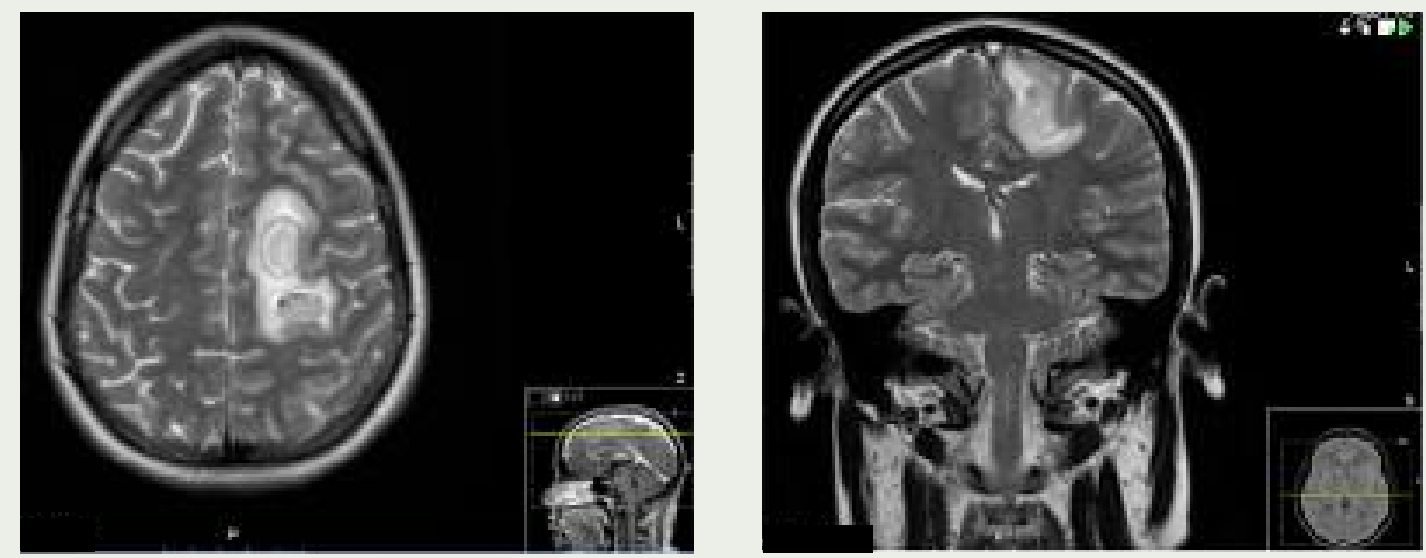

D12 TC-CE de controlo por persistência de cefaleias e possível hemianopsia homónima direita: "Diminuição da extensão das alterações prévias" e "edema da papila". Iniciou terapêutica com acetazolamida.

D13 Retirou anel vaginal e iniciou métodos contracetivos de barreira.

D15 Alta

Legenda: D - dia de internamento; TC-CE - tomografia computorizada crânio encefálica; EEG - eletroencefalograma; RMN-CE - ressonância magnética nuclear crânio encefálica.

lógicos, embora com algumas intercorrências (Quadro I). Foi ainda realizado o estudo de trombofilias, que revelou inibidor lúpico positivo, anticorpos antinucleares positivos (1/320 padrão mosqueado), anticorpo anti- $\beta 2$-glicoproteina discretamente elevado, com restante estudo normal, tendo-se estabelecido o diagnóstico de síndroma antifosfolipídica.

Teve alta ao $15^{\circ}$ dia de internamento, clinicamente melhorada, força muscular no membro superior direito grau 4 em 5 e membro inferior direito grau 5 em 5; hipostesia marcada no membro superior direito, ligeira no membro inferior direito; parcialmente autónoma para as atividades de vida diária (NIHSS:2 e mRankin:2); e com os diagnósticos de síndroma antifosfolipídica, trombose dos seios venosos (terços anterior e médio do seio longitudinal superior) com transformação hemorrágica e, como complicação, crise convulsiva tónico-clónica generalizada.

Após a alta manteve terapêutica anticoagulante com varfarina, com razão normalizada internacional (INR) 


\begin{tabular}{|c|c|c|}
\hline $\begin{array}{l}\text { Critérios } \\
\text { clínicos de } \\
\text { Sydney }\end{array}$ & \multicolumn{2}{|c|}{$\begin{array}{l}\text { 1. Trombose vascular: } \\
\text { Um ou mais episódios de trombose arterial, venosa ou de pequenos vasos em qualquer tecido ou órgão, } \\
\text { confirmado por imagem, estudo Doppler ou histopatologia. Exceto a trombose venosa superficial. } \\
\text { 2. Morbilidade durante a gravidez: } \\
\text { (a) Um ou mais abortos de feto morfologicamente normal (documentada por ecografia ou por exame direto) } \\
\text { após as } 10 \text { semanas de gestação. OU, } \\
\text { (b) Um ou mais partos prematuros (<34 semanas) de recém-nascidos morfologicamente normais devido a } \\
\text { pré-eclâmpsia grave ou eclâmpsia ou insuficiência placentária grave. OU, } \\
\text { (c) Três ou mais abortos espontâneos consecutivos antes das } 10 \text { semanas de gestação, com alterações maternas } \\
\text { anatómicas ou hormonais e excluídas alterações cromossómicas paternas e maternas. }\end{array}$} \\
\hline $\begin{array}{l}\text { Critérios } \\
\text { laboratoriais }\end{array}$ & $\begin{array}{l}\text { (a) Inibidor lúpico } \\
\text { (b) Anticorpo antiß2glicoproteina (IgG e IgM) } \\
\text { (c) Anticorpo anticardiolipina (IgG e IgM) }\end{array}$ & $\begin{array}{l}\text { Confirmado após um período de } 12 \text { semanas } \\
\text { Confirmado após um período de } 12 \text { semanas } \\
\text { Títulos > Percentil } 99 \\
\text { Confirmado após um período de } 12 \text { semanas } \\
\text { Títulos > Percentil } 99\end{array}$ \\
\hline
\end{tabular}

Adaptado de: Devreese K, Hoylaerts MF. Challenges in the diagnosis of the antiphospholipid syndrome. Clin Chem. 2010;56(6):930-40.

alvo de 2,5, fisioterapia diária para recuperação dos défices motores e consulta de seguimento em medicina interna, neurologia, neuro-oftalmologia e ginecologiaobstetrícia.

Ao segundo mês após a alta, a doente recorreu à consulta de saúde de adultos na USF para renovação de certificado de incapacidade temporária para o trabalho. Apresentava ligeiro desvio da comissura labial para a esquerda e ligeiro apagamento do sulco nasogeniano direito; hipostesia facial direita ligeira; força muscular no hemicorpo esquerdo 5 em 5 ; força muscular no hemicorpo direito: 5 em 5 na mão e membro inferior direito e de 4 em 5 no braço e antebraço; hipostesia ligeira do membro superior direito; reflexo cutâneo plantar indiferente à direita e flexão à esquerda (NIHSS:2 e mRankin:1). Estas alterações, por exigirem apoio familiar, foram fatores promotores da resolução dos conflitos familiares existentes entre Maria, o namorado e a mãe e a dinâmica familiar entre estes elementos tornou-se boa.

\section{COMENTÁRIO}

O diagnóstico da síndroma antifosfolipídica requer a presença de, pelo menos, um critério clínico e um critério laboratorial (Quadro II). A avaliação laboratorial deve ser confirmada às 12 semanas e deve limitar-se apenas aos pacientes que preenchem os critérios clíni- cos, já que foi demonstrada a presença de anticorpos antifosfolipídicos em 1 a 5\% da população saudável, sem risco trombótico acrescido. ${ }^{3-4}$

Dado o risco pró-trombótico da síndroma antifosfolipídica, a anticoagulação oral é o tratamento de eleição. O tipo, duração e intensidade da terapêutica anticoagulante permanecem questões controversas, sendo necessário averiguar, caso a caso, as vantagens da anticoagulação e os riscos de hemorragia.

A British Society of Haematology recomenda um INR alvo de 2,5 para pacientes com trombose venosa associada à síndroma antifosfolipídica e um INR alvo de 3,5 para os doentes com recorrência de eventos trombóticos mesmo sob terapêutica anticoagulante. ${ }^{7-8}$

O AVC é a forma de apresentação da síndroma antifosfolipídica em 13,5 a $15 \%$ dos doentes, com um atingimento predominante da artéria cerebral média, embora qualquer território possa ser afetado. ${ }^{5}$

A trombose dos seios venosos é uma entidade rara, ${ }^{5}$ associada a manifestações clínicas inespecíficas, como a cefaleia (>80\%), convulsões (40\%), hemiparesia ( $40 \%)$, alteração do estado de consciência (15-20\%) e edema da papila (20-30\%), o que, aliado à possibilidade de permanecer oculta na TC nas primeiras 24 a 48 horas, torna o seu diagnóstico um verdadeiro desafio..$^{9-10}$

Comparativamente aos adultos e idosos, o AVC em 
QUADRO III. Causas e fatores de risco para AVC isquémico em adolescentes e adultos jovens

\section{Arteriais}

1. Disseção da artéria cerebral

2. Síndroma cerebral vasoconstritivo reversível

3. Doença de Moyamoya

4. Doença das células de Sickle

5. Arteriopatia cerebral transitória da infância

6. Aterosclerose prematura, lipo-hialinose

7. Arteriopatia induzida pela radiação

8. Enxaqueca com aura

9. Uso ilícito de drogas (e.g., cocaína, anfetaminas, ecstasy)
10. Arteriopatia infeciosa (e.g., varicela, tuberculose, sífilis, vírus da imunodeficiência humana)

11. Arteriopatia inflamatória (e.g., arterite de Takayasu, arterite de células gigantes, angeíte primária do SNC, poliarterite nodosa, doença de Behçet)

12. Genética (e.g., doença de Fabry, displasia fibromuscular, encefalopatia mitocondrial, hiperhomocisteinémia, neurofibromatose tipo1)

\section{Cardíacas}

1. Foramen ovale patente

2. Doença cardíaca congénita

3. Endocardite infecciosa e não infecciosa

4. Doença valvular reumática

5. Pós-cirurgia cardíaca ou intervenção coronária percutânea
6. Arritmia (e.g., fibrilação auricular, síndroma do nódulo sinusal)

7. Tumor cardíaco (e.g., mixoma auricular, fibroelastoma papilar)

8. Enfarte miocárdio recente

9. Cardiomiopatia dilatada

\section{Hematológicas}

1. Trombocitopenia induzida pela heparina

2. Deficiência da proteína $S$, proteína $C$ ou antitrombina. Mutação Factor $V$ de Leiden

3. Estado de hipercoagulabilidade adquirido (e.g., cancro, gravidez, anticoncetivos orais combinados, uso de esteroides anabolizantes e eritropoietina, síndroma nefrótico, síndroma antifosfolipídica)
4. Doenças hematológicas primárias (e.g., policitemia vera, trombocitopenia essencial, hemoglobinúria noturna paroxística, púrpura trombótica trombocitopénica, leucemia, linfoma, mieloma múltiplo)

Adaptado de:Yager PH, Singhal AB, Nogueira RG. Case records of the Massachusetts General Hospital. Case 31-2012: an 18-year-old man with blurred vision, dysarthria, and ataxia. N Engl J Med. 2012;367(15):1450-60.

doentes jovens tem um maior impacto socioeconómico. ${ }^{11} \mathrm{Na}$ trombose dos seios venosos, os fatores de risco para um desfecho desfavorável foram identificados como sendo o sexo masculino, idade $>37$ anos, coma, perturbação do estado mental, hemorragia intracraniana à admissão, trombose do sistema venoso profundo, infeção do sistema nervoso central e cancro. ${ }^{12}$ Destes, identificam-se a perturbação do estado mental e a hemorragia intracraniana à admissão como fatores de risco de mau prognóstico no doente descrito.

O diagnóstico precoce do AVC nos jovens permanece difícil, seja pela ausência de sensibilização ou de fatores de risco, infrequência ou diagnósticos mimetizantes (como a síndroma vestibular, enxaqueca, infeção do sistema nervoso central, tumor cerebral, hipoglicemia, encefalopatia hipertensiva, gastroenterite ou somatização). ${ }^{11}$ No entanto, aliado às causas inerentes de AVC nos jovens adultos (Quadro III), a emergência de fatores de risco resultantes da atual epidemia da obesidade leva a uma imperiosa necessidade de sensibilização da equipa de saúde.

Relativamente à história ginecológica e obstétrica, na síndroma antifosfolipídica os métodos contracetivos de barreira são os únicos que estão recomendados. A síndroma antifosfolipídica não é contraindicação para a gravidez, mas associa-se a complicações, nomeadamente abortos de repetição, prematuridade, insuficiência placentar, pré-eclâmpsia, eclâmpsia, síndroma HELLP (hemólise, elevação das enzimas hepáticas e trombocitopenia), eventos trombóticos vasculares e, em casos raros, a síndroma antifosfolipídica catastrófica com coagulação intravascular disseminada e uma 
taxa de mortalidade de $50 \% .{ }^{13}$ Os anticoagulantes orais, por serem teratogénicos, devem ser substituídos imediatamente após confirmação da gravidez por heparina de baixo peso molecular (HBPM) e ácido acetilsalicílico (AAS) em baixa dose. A probabilidade de a gravidez decorrer com sucesso na ausência de terapêutica é de $30 \%, 50 \%$ se realizada terapêutica única com HBPM e 70\% se terapêutica dupla com HBPM e AAS. A HBPM e o AAS deverão ser mantidos até seis semanas após o parto, altura em que pode ser retomada a anticoagulação oral. Nas mães a amamentar, o recém-nascido deve realizar suplementação com vitamina $\mathrm{K}^{13}$

\section{REFERÊNCIAS BIBLIOGRÁFICAS}

1. Silva FF, Levy RA, Carvalho JF. Cardiovascular risk factors in the antiphospholipid syndrome. J Immunol Res. 2014;2014:ID621270.

2. Alchi B, Griffiths M, Jayne D. What nephrologists need to know about antiphospholipid syndrome. Nephrol Dial Transplant. 2010;25(10):3147-54.

3. Pinto-Almeida T, Caetano M, Sanches M, Selores M. Cutaneous manifestations of antiphospholipid syndrome: a review of the clinical features, diagnosis and management.Acta Reumatol Port. 2013;38(1):108.

4. Koniari I, Siminelakis SN, Baikoussis NG, Papadopoulos G, Goudevenos J, Apostolakis E. Antiphospholipid syndrome; its implication in cardiovascular diseases: a review. J Cardiothorac Surg. 2010;5:101.

5. Carecchio M, Cantello R, Comi C. Revisiting the molecular mechanism of neurological manifestations in antiphospholipid syndrome: beyond vascular damage. J Immunol Res. 2014;2014:ID239398.

6. Vicente I, Fernandes C, Fortuna J, Sá A, Ferreira O, Miraldo M. Síndro- me antifosfolipídico. Med Interna. 1999;6(4):254-7.

7. Henriques CC, Lourenço F, Lopéz B, Panarra A, Riso N. Antiphospholipid syndrome and recurrent thrombosis: limitations of current treatment strategies. BMJ Case Rep. 2012;2012.

8. Lim W. Antiphospholipid syndrome. ASH Education Book. 2013;2013(1):675-80.

9. Tanislav C, Siekmann R, Sieweke N, Allendörfer J, Pabst W, Kaps M, et al. Cerebral vein thrombosis: clinical manifestation and diagnosis. BMC Neurol. 2011;11:69.

10. Ducla-Soares JL. Semiologia médica: princípios, métodos e interpretação. Lisboa: Lidel; 2007. ISBN 9789727574261

11. Singhal $A B$, Biller J, Elkind MS, Fullerton HJ, Jauch EC, Kittner SJ, et al. Recognition and management of stroke in young adults and adolescents. Neurology. 2013;81(12):1089-97.

12. Ferro JM, Canhão P, Stam J, Bousser MG, Barinagarrementeria F. Prognosis of cerebral vein and dural sinus thrombosis: results of the International Study on Cerebral Vein and Dural Sinus Thrombosis (ISCVT). Stroke. 2004;35(3):664-70.

13. Marchetti T, Cohen M, de Moerloose P. Obstetrical antiphospholipid syndrome: from the pathogenesis to the clinical and therapeutic implications. Clin Dev Immunol. 2013;2013:ID159124.

\section{CONFLITOS DE INTERESSE}

Os autores declaram não ter conflitos de interesse.

\section{ENDEREÇO PARA CORRESPONDÊNCIA \\ Lisa Teresa Moreira \\ ACeS Tâmega II, Vale do Sousa Sul \\ E-mail: lisamoreira1@gmail.com}

Recebido em 25-03-2016

Aceite para publicação em 29-01-2017

\section{ABSTRACT}

\section{ANTIPHOSPHOLIPID SYNDROME: A CASE REPORT}

Introduction: Antiphospholipid syndrome is an autoimmune disorder that increases the risk of thrombosis. It has multiple clinical manifestations, making the diagnosis a challenge.

Case report: A 25 year-old Caucasian woman presented with right frontal headache, radiating to the eyes, with loss of sensation on the right side of the face and flattening of the right naso-labial fold. Computerized tomography of the head did not reveal acute alterations. Loss of sensation on the right side of the body appeared after 48 hours. Computerized tomography revealed thrombosis of the anterior and medial third of superior longitudinal sinus. Further investigation revealed the presence of lupus anticoagulant, antinuclear antibodies (titers of $1 / 320$ ), and anti- $\beta 2$-glycoprotein antibodies confirming the diagnosis of antiphospholipid syndrome.

Comment: Stroke is the first manifestation of the antiphospholipid syndrome in $13.5 \%$ to $15 \%$ of cases, preferentially affecting the middle cerebral artery. Sinus thrombosis is a rare presentation associated with non-specific symptoms. Early diagnosis of stroke in young people remains difficult. Health providers need to be aware of this syndrome with the increase in risk factors such as obesity among the young.

Keywords: Antiphospholipid syndrome; Antibodies, Antiphospholipid; Stroke; Sinus thrombosis, Intracranial. 